\title{
STUDI KINETIKA PENGHILANGAN AIR KRISTAL LIMONIT MENJADI HEMATIT PADA ATMOSFER INERT
}

\author{
Kinetics Study on Water Crystal Removal of Limonite Into Hematite \\ on Inert Atmosphere
}

\author{
SURATMAN \\ Puslitbang Teknologi Mineral dan Batubara \\ Jalan Jenderal Sudirman 623 Bandung 40211 \\ Telp. (022) 6030483, Fax. (022) 6003373 \\ e-mail: suratman@tekmira.esdm.goid
}

\begin{abstract}
ABSTRAK
Kebutuhan besi baja untuk pembangunan di Indonesia selalu meningkat dari tahun ke tahun. Untuk itu, perlu dicari alternatif bahan baku lokal pembuatan pelet di antaranya pemanfaatan mineral limonit dengan mengubahnya menjadi mineral hematit dan dilanjutkan dengan proses konsentrasi, sehingga memiliki kandungan Fe yang lebih tinggi. Dalam penelitian ini dilakukan penghilangan air kristal bijih limonit dan mengubahnya menjadi hematit. Percobaan dilakukan pada temperatur $250,300,350,450$ dan $500^{\circ} \mathrm{C}$, selama 60 menit dengan suplai nitrogen 1 liter/menit. Hasil percobaan menunjukkan temperatur proses optimal adalah $350^{\circ} \mathrm{C}$ dengan $\%$ Berat percontoh yang hilang 11,3\% dan meningkatkan kadar Fe total dari 50 hingga $56,4 \%$. Produk ini belum memenuhi persyaratan sebagai bahan baku pelet. Dari hasil studi kinetika penghilangan air kristal mineral limonit ini, reaksi pengubahan mineral limonit menjadi hematit terkendali oleh proses difusi pada temperatur $250^{\circ} \mathrm{C}$ dan $300^{\circ} \mathrm{C}$.
\end{abstract}

Kata kunci : bijih laterit, limonit, tudung besi, hematit, air kristal, kinetika.

\begin{abstract}
Indonesia demand of stainless steel for country's development always increase continuously. Therefore, it is necessary to find an alternative raw material of pellets for stainless industry. Limonite can be converting to hematit by dehydration of crystal water contained in limonit, then its iron grade can be increased through concentation method. In this research, converting limonite into hematite was carried out at various temperatures of $250,300,350,450$, and $500^{\circ} \mathrm{C}$, for 60 minutes, using ore with particle size -325 mesh, and nitrogen flow rate of 1 litre/minute. The results show that $350^{\circ} \mathrm{C}$ was the optimum temperature with \% sample loss $11,3 \%$ and increased \% Fetotal to $56,4 \%$. However, this product has not meet the requirement as raw material for pellet. Based on kinetics studies, the reaction of convertion limonite into hematite was controlled by difusion process at temperatur of 250 and $300^{\circ} \mathrm{C}$.
\end{abstract}

Keywords : lateritic ore, limonite, iron cap, ferricrete, hematite, crystalline water, kinetics

\section{PENDAHULUAN}

Kebutuhan besi baja untuk pembangunan di Indonesia selalu meningkat dari tahun ke tahun. Untuk konsumsi pada 2015 mencapai 16.599 juta ton dan tahun 2016 diperkirakan sebesar 17.595 juta ton. Sedangkan kapasitas produksi seluruh produk baja nasional di tahun 2015 dan 2016 sekitar 7.004 juta ton sehingga akan terjadi kekurangan suplai baja sebesar 10.591 juta ton yang akan dipenuhi dengan membuka impor baja. Akibatnya baja impor 
menguasai 45 sampai 50 persen pasar baja Indonesia. Kondisi ini, menjadikan persaingan bisnis baja di pasar domestik semakin berat karena baja produk dalam negeri yang bahan bakunya 100 persen impor, kalah bersaing dengan baja impor yang harganya lebih murah seperti yang sudah terjadi sejak tahun 2014, dan terus berlangsung sampai saat ini.

Bijih besi laterit, dengan deposit sebesar $1.778,4$ juta ton letaknya tersebar di Kalimantan Selatan, Sulawesi Selatan, Sulawesi Tenggara, Maluku Utara dan Papua barat. Biji Besi laterit merupakan hasil pelapukan sehingga banyak didominasi oleh mineralmineral goetit dan mengandung nikel. Kadar biji besi laterit bervariasi dan dapat juga ditingkatkan kadarnya dengan berbagai macam teknologi peningkatan kadar (Pardiarto, 2011).

Potensi deposit bijih besi laterit yang cukup besar dapat menjadi alternatif bahan baku lokal untuk mengembangkan industri baja nasional. Untuk itu diperlukan upaya pengolahan bijih besi laterit agar mencapai persyaratan sebagai bahan baku pembuatan baja. Salah satu alternatif yang mungkin dilakukan adalah mengubah mineral limonit (goetit) menjadi mineral hematit dan dilanjutkan dengan proses konsentrasi, sehingga memiliki kandungan $\mathrm{Fe}$ yang lebih tinggi. Proses tersebut dapat dilakukan melalui proses penghilangan air kristal (kalsinasi, dehidrasi) mineral limonit sehingga dihasilkan produk dehidrasi oksida besi (hematit) (de Faria dan Lopes, 2007; Rizov, 2012; Jang $d k k$., 2014). Mineral limonit dapat diubah secara kontinu menjadi bentuk oksida besi lainnya pada kondisi operasi tertentu dan salah satunya adalah oksida besi hematit yang terbentuk melalui pemanasan dengan bantuan hembusan gas inert nitrogen (Epikhin dan Krylova, 2003) dengan tahap perubahan sebagai berikut:

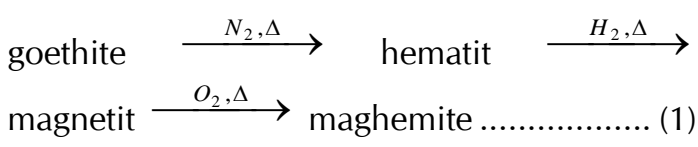

Pemanfaatan mineral limonit untuk kepentingan industri besi dan baja Indonesia dapat dimungkinkan, mengingat ketersediaannya yang cukup melimpah di beberapa daerah di Indonesia. Potensi endapan bijih laterit di Indonesia cukup besar dengan cadangan 1.576 juta ton bijih (Astuti et al.,
2015), yaitu terdapat di Pulau Sebuku, Gunung Kukusan, Geronggang (Kalimantan Selatan), Pomala (Sulawesi Tenggara), Halmahera (Maluku Utara), Sampit (Kalimantan Tengah) dan Soroako (Sulawesi Selatan). Bijih laterit umumnya hanya dimanfaatkan sebagai sumber utama nikel, namun dengan adanya kandungan besi yang juga cukup tinggi, maka bijih laterit memungkinkan untuk dimanfaatkan sebagai salah satu alternatif sumber besi untuk industri besi dan baja.

Lapisan bijih laterit terdiri dari beberapa zona seperti terlihat pada Tabel 1 (Dzemua dan Gleeson, 2012; Elias, 2013). Pada zona limonit, kandungan besi dapat mencapai 35$45 \%$, bahkan ada yang melebihi $50 \%$. Zona limonit terstratifikasi seperti halnya lapisan bijih laterit. Bagian atas zona limonit dominan ditempati oleh mineral limonit, dan terkadang limonit yang telah lama terendapkan juga mengandung mineral hematit. Mineral limonit merupakan bentuk hidrat dari mineral hematit dengan rumus kimia $\mathrm{Fe}_{2} \mathrm{O}_{3} . \mathrm{H}_{2} \mathrm{O}$ atau $\mathrm{FeOOH}$. Kandungan besi di dalam mineral ini mencapai $62,9 \%$ Fe dalam keadaan murni.

Penelitian ini bertujuan untuk mengetahui termodinamika dan kinetika reaksi proses penghilangan air kristal mineral limonit sebagai pengaruh dari temperatur terhadap perolehan hematit. Hematit yang dihasilkan serta peningkatan kadar besinya diharapkan memiliki karakteristik konsentrat besi yang dapat memenuhi syarat sebagai bahan baku untuk industri besi dan baja dengan kadar Fe total minimum 63\% (Gilroy, 2014).

\section{METODE}

\section{Bahan}

Bahan baku yang digunakan pada percobaan ini adalah bijih limonit dan gas nitrogen teknis $\left(99,9 \% \quad N_{2}\right)$. Bijih limonit diperoleh dari lapisan bijih laterit di daerah penambangan PT Vale Tbk, Sorowako, Sulawesi Selatan.

Percontoh bijih limonite dikeringkan di dalam oven pada suhu $\pm 105^{\circ} \mathrm{C}$ untuk menghilangkan kelembaban, ditimbang, lalu diayak secara basah pada ayakan berukuran 140-200-270-325 mesh (mengacu pada standar ASTM (American Standard for Testing 
Material) dan BS (British Standard) agar lebih memudahkan memisahkan mineral dengan ukuran yang halus. Jumlah bijih limonit yang diperoleh pada masing-masing fraksi ukuran ditimbang dan dihitung dalam persen (\%) berat tertampung, kemudian dimasukkan ke dalam desikator.

Fraksi ukuran dengan persen (\%) berat tertampung yang terbesar sebanyak $91,15 \%$ (325 mesh / kurang dari $45 \mu \mathrm{m}$ ) digunakan sebagai umpan percobaan. Percontoh tersebut dianalisis kimia (AAS dan Volumetri) dan mineralogi (XRD dan Optik-mineragrafi) untuk mengetahui kadar Fe total, $\mathrm{SiO}_{2}, \mathrm{Al}_{2} \mathrm{O}_{3}$, dan $\mathrm{Ni}$ serta untuk melihat komposisi senyawanya.

Percontoh sebanyak 15 gram ditempatkan ke dalam cawan baja stainless steel, kemudian dimasukkan tepat di tengah tanur tabung. Gas nitrogen dilewatkan ke dalam tanur tabung dan sebelum percobaan dimulai, dilakukan pengkondisian dengan menggunakan gas nitrogen selama 5 menit. Gas nitrogen yang akan dilewatkan ke dalam tanur tabung sebelumnya melewati gelas berisi silika gel, untuk menyerap kandungan air yang terdapat di dalam gas nitrogen. Produk proses penghilangan air kristal yang dihasilkan kemudian ditimbang. Percobaan dilakukan dengan menggunakan fraksi bijih ukuran -325 mesh, debit nitrogen $1 \mathrm{~L} /$ menit, berlangsung pada temperatur 250, 300, 350, 450, dan $500^{\circ} \mathrm{C}$ selama 60 menit.

Nilai optimal yang diperoleh dari pengaruh temperatur ditentukan melalui parameter \% Berat percontoh yang hilang dari produk yang dihasilkan serta peningkatan \%Fetotal. Khusus untuk produk yang diperoleh pada suhu optimal dilakukan analisis kimia \%Fetota, sebagai faktor koreksi terhadap \%Fetotal yang diperoleh melalui perhitungan.

Persen (\%) Berat percontoh yang hilang ditentukan dengan menggunakan rumus berikut:

$$
\begin{aligned}
& \text { \% Berat percontoh yang hilang }= \\
& \frac{\mathrm{W}_{\mathrm{g}, \mathrm{awal}}-\mathrm{W}_{\mathrm{g}, \mathrm{akhir}}}{\mathrm{W}_{\mathrm{g} \text {,awal }}} \times 100 \%
\end{aligned}
$$

Perhitungan \% Berat percontoh yang hilang dimaksudkan untuk menentukan besarnya molekul air yang lepas selama proses berlangsung. Limonit merupakan satu-satunya mineral hidrat di dalam bijih ini, maka dapat dikatakan selama proses berlangsung, hanya terjadi pelepasan molekul air dari mineral limonit.

Persen (\%) Fe total perhitungan ditentukan dengan menggunakan rumus berikut:

$\%$ Fe total perhitungan $=$

$\frac{\mathrm{W}_{\text {g,awal }}}{\mathrm{W}_{\mathrm{g}, \text { akhir }}} \times \%$ Fe Sampel Awal

Keterangan :

$\mathrm{W}_{\mathrm{g} \text {, awal }}=$ berat umpan yang digunakan untuk proses pengilangan air kristal

$\mathrm{W}_{\mathrm{g}, \text { akhir }}=$ berat produk setelah proses penghilangan air kristal

Untuk menentukan produk yang terbentuk dari proses penghilangan air kristal mineral limonit adalah hematit, dilakukan analisis mineralogi menggunakan XRD dan mengukur perubahan parameter besar kemagnetan terhadap percontoh hasil percobaan. Kisaran kuat medan magnet untuk pemisahan mineral hematit yaitu 13.000-18.000 Gauss (Ezhov dan Shvaljov, 2015). Hal ini juga untuk melihat pengaruh proses penghilangan air kristal terhadap sifat kemagnetan.

\section{Analisis Produk}

Untuk mengidentifikasi produk proses penghilangan air kristal, dilakukan analisis komposisi mineralogi dengan XRD dan Optikmineragrafi untuk melihat senyawa yang terbentuk setelah proses. Juga dilakukan analisis komposisi kimia \%Fetotal dari produk.. Perubahan kadar $\mathrm{Fe}$ di dalam produk dibandingkan dengan kadar awal percontoh. Analisis ini bertujuan untuk memeriksa ketepatan besarnya jumlah \% Berat percontoh yang hilang yang dianalisis dengan menggunakan metode penimbangan berat percontoh awal dan berat produk serta sebagai faktor koreksi terhadap \%Fetotal yang diperoleh melalui perhitungan.

Di samping itu dilakukan pula penentuan pengurangan berat produk yang diperoleh akibat pengaruh lepasnya molekul air dari mineral limonit membentuk hematit (\% Berat percontoh yang hilang). Dari data pengurangan 
berat dapat ditentukan perbandingan mol molekul air $\left(\mathrm{H}_{2} \mathrm{O}\right)$ dan hematit $\left(\mathrm{Fe}_{2} \mathrm{O}_{3}\right)$. Secara teoritis perbandingan jumlah mol $\mathrm{H}_{2} \mathrm{O}$ dengan $\mathrm{Fe}_{2} \mathrm{O}_{3}$ pada mineral limonit adalah $1: 1$, dengan reaksi sebagai berikut:

$\mathrm{Fe}_{2} \mathrm{O}_{3} . \mathrm{H}_{2} \mathrm{O}_{(\mathrm{p})} \rightarrow \mathrm{Fe}_{2} \mathrm{O}_{3}(\mathrm{p})+\mathrm{H}_{2} \mathrm{O}_{(\mathrm{g})}$

Dari perbandingan mol teoritis tersebut dapat diketahui bahwa proses dehidrasi mineral limonit akan berlangsung sempurna setelah percontoh kehilangan berat sebesar $10 \%$ (Strezov dkk., 2011; Jang $d k k .$, 2014).

\section{HASIL DAN PEMBAHASAN}

\section{Analisis Mineralogi}

Hasil analisis kimia terhadap percontoh dengan fraksi ukuran -325 mesh yang dilakukan di Puslitbang Tekmira, mineral limonit mengandung Fe total sebesar 50\%. Mineral yang dominan dalam bijih adalah limonit, terkandung sedikit hematit serta pengotor kuarsa $\left(\mathrm{SiO}_{2}\right)$ dan alumina $\left(\mathrm{Al}_{2} \mathrm{O}_{3}\right)$ seperti ditunjukkan oleh hasil analisis XRD (X-Ray Diffraction) terhadap percontoh (Gambar 1). Adapun hasil analisis komposisi kimia (Tabel 1 dan 2) menunjukkan komposisi $\mathrm{SiO}_{2}$ dan $\mathrm{Al}_{2} \mathrm{O}_{3}$ pada bijih limonit masing-masing sebesar $1,72 \%$ dan $9,02 \%$
Analisis optik-mineragrafi menunjukkan adanya perubahan fisik secara mikroskopis dari mineral limonit setelah dilakukan proses penghilangan air kristal, seperti diperlihatkan pada Gambar 2.

Terlihat bahwa percontoh awal sebelum proses memiliki bentuk yang tidak beraturan dengan warna yang cenderung terang, sedangkan setelah proses, percontoh memiliki bentuk bulat yang lebih beraturan dengan warna yang lebih gelap.

\section{Pengaruh Temperatur}

Temperatur sangat berpengaruh terhadap spontanitas reaksi penghilangan air mineral limonit. Dari data perhitungan perubahan energi bebas standar reaksi $\Delta \mathrm{G}_{\text {Reaksi, diperoleh }}^{\circ}$ bahwa spontanitas reaksi penghilangan air kristal mineral limonit akan semakin tinggi dengan dinaikkannya temperatur reaksi, ditandai oleh nilai $\Delta \mathrm{G}_{\text {Reaksi }}^{\circ}$ yang semakin negatif. Artinya reaksi akan semakin mudah terjadi pada temperatur yang lebih tinggi. Hasil percobaan dengan memvariasikan temperatur diperlihatkan pada Gambar 3 dan 4. Percobaan dilakukan pada suhu 250, 300, 350, 450, dan $500{ }^{\circ} \mathrm{C}$ selama 60 menit dengan debit nitrogen 1 liter/menit. Peningkatan temperatur meningkatkan \% Berat percontoh yang hilang serta \% Fe perhitungan.

Tabel 1. Komposisi unsur/senyawa pada masing-masing zona di dalam endapan bijih laterit (Dzemua dan Gleeson, 2012; Elias, 2013).

\begin{tabular}{cccccc}
\hline Zona & $\mathrm{Ni}$ & $\mathrm{Co}$ & $\mathrm{Fe}$ & $\mathrm{Cr} 2 \mathrm{O} 3$ & $\mathrm{MgO}$ \\
\hline Ferricrete & $<0,8 \%$ & $<0,1 \%$ & $>50 \%$ & $>1 \%$ & $<0,5 \%$ \\
Limonit & $0,8-1,5 \%$ & $0,1-0,2 \%$ & $40-50 \%$ & $2-5 \%$ & $0,5-5 \%$ \\
Saprolit & $1,5-3 \%$ & $0,02-0,1 \%$ & $10-40 \%$ & $1-2 \%$ & $5-35 \%$ \\
Bedrock & $0,25 \%$ & $0,01-0,02 \%$ & $5 \%$ & $0,2-1 \%$ & $35-45 \%$ \\
\hline
\end{tabular}

Tabel 2. Komposisi kimia percontoh laterit ferricrete (limonit) ukuran zarah -325\#

\begin{tabular}{|c|c|c|c|c|c|c|c|c|c|c|}
\hline \multirow{2}{*}{$\begin{array}{l}\text { Ukuran Zarah } \\
\text { (mesh) }\end{array}$} & \multicolumn{9}{|c|}{ Komposisi Kimia (\%) } & \multirow{2}{*}{$\begin{array}{c}\text { Jenis } \\
\text { Mineral }\end{array}$} \\
\hline & $\mathrm{Fe}$ & $\mathrm{Ni}$ & $\mathrm{Cr}$ & V & $\mathrm{SiO}_{2}$ & $\mathrm{Al}_{2} \mathrm{O}_{3}$ & $\mathrm{CaO}$ & $\begin{array}{c}\text { Mn } \\
\mathrm{O}\end{array}$ & $\mathrm{MgO}$ & \\
\hline-325 & 49.58 & 0.536 & 0.121 & 0.184 & 1.72 & 9.02 & 0.06 & $\begin{array}{c}1.1 \\
3 \\
\end{array}$ & 0.87 & Goethite \\
\hline
\end{tabular}




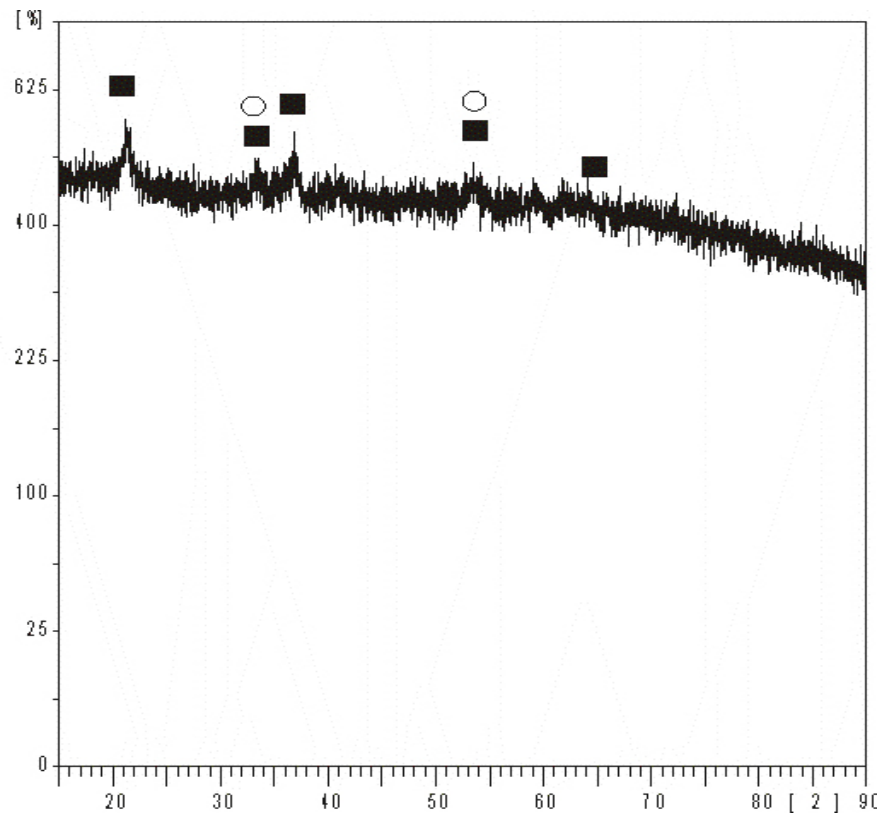

Gambar 1. Hasil analisis XRD percontoh (tanda (ם) limonit dan $(\mathrm{O})$ kuarsa)

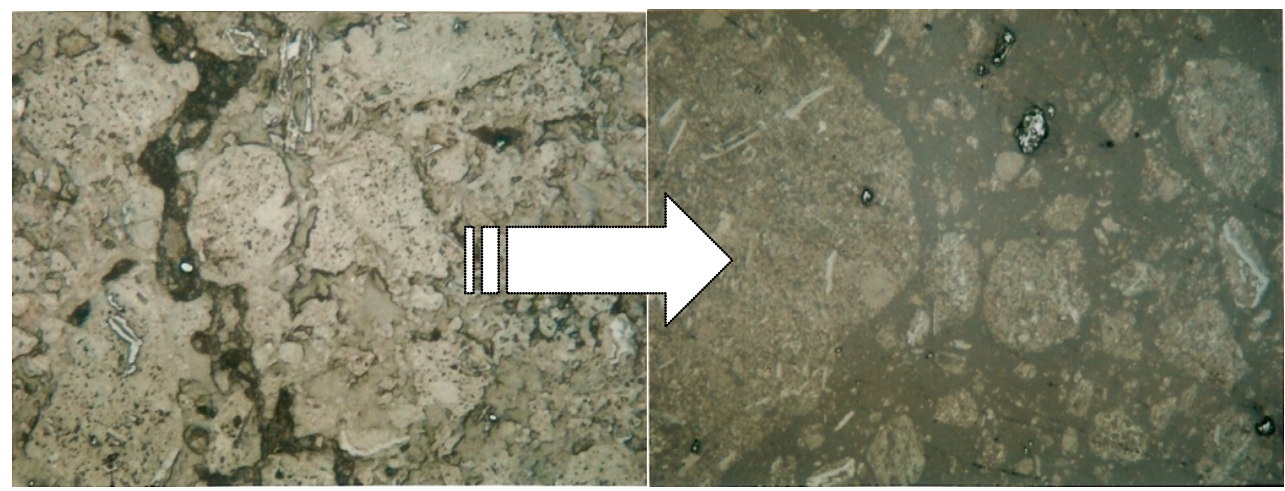

(a)

(b)

Gambar 2. Analisis optik-mineragrafi (a) percontoh sebelum proses (b) percontoh setelah proses pada $\mathrm{T}=350^{\circ} \mathrm{C}, \mathrm{t}=60$ menit, dan debit nitrogen 1 liter/menit

Pengecualian pada temperatur $250^{\circ} \mathrm{C}$ dan $300^{\circ} \mathrm{C}$ nilai \% Berat percontoh yang hilang melebihi nilai stoikiometri perbandingan mol 1:1 $\mathrm{Fe}_{2} \mathrm{O}_{3}$ dan $\mathrm{H}_{2} \mathrm{O}$ yaitu sebesar $10 \%$. Nilai $\%$ Berat percontoh yang hilang yang melebihi nilai stoikiometrinya mungkin disebabkan adanya kelebihan air molekul di dalam mineral limonit. (Jang $d k k$. (2014) menyatakan bahwa di alam mineral limonit hadir tidak dalam bentuk stoikiometrinya (adanya kelebihan air molekul di dalam mineral limonit). Mineral limonit yang terbentuk dari ion ferrous $\left(\mathrm{Fe}^{2+}\right)$ memiliki kelebihan air molekul (non-stoikiometri $\mathrm{OH}$ ) yang lebih besar dan suhu dehidrasi yang lebih rendah dibandingkan dari ion feri $\left(\mathrm{Fe}^{3+}\right)$. Di alam, mineral limonit terbentuk akibat proses pelarutan atau pelapukan batuan peridotit. Pelarutan batuan peridotit pada $\mathrm{pH}$ air tanah tertentu dapat menghasilkan ion $\mathrm{Fe}^{2+}, \mathrm{Fe}^{3+}$, $\mathrm{FeOH}^{2+}$, dan $\mathrm{Fe}(\mathrm{OH})_{2}{ }^{+}$, namun ion $\mathrm{Fe}^{2+}$ memiliki daerah kestabilan ion yang lebih besar dibandingkan $\mathrm{Fe}^{3+}, \mathrm{FeOH}^{2+}$, dan $\mathrm{Fe}(\mathrm{OH})_{2}{ }^{+}$seperti terlihat pada Gambar 3, sehingga pada $\mathrm{pH}$ yang sama ion $\mathrm{Fe}^{2+}$ akan cenderung lebih stabil dibandingkan $\mathrm{Fe}^{3+}$, $\mathrm{FeOH}^{2+}$, dan $\mathrm{Fe}(\mathrm{OH})_{2}{ }^{+}$dan menjadi ion besi yang dominan. 


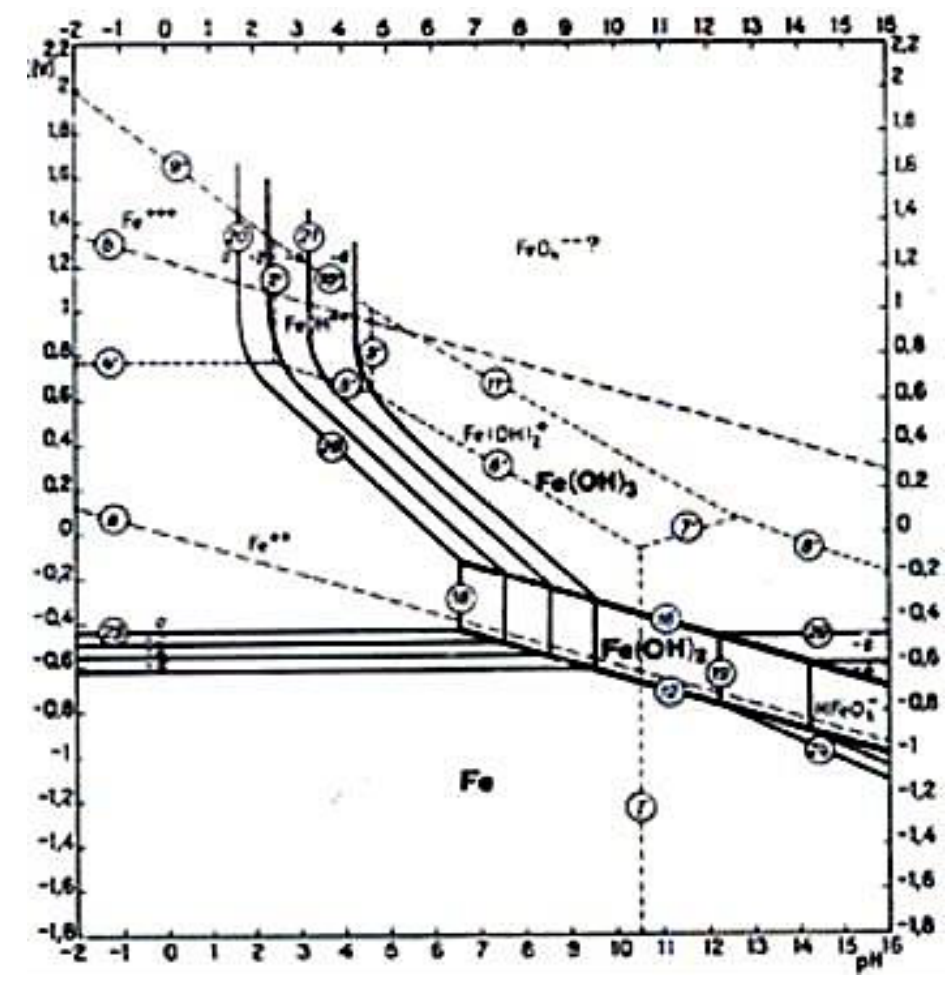

Gambar 3. Diagram Eh-pH sistem $\mathrm{Fe}-\mathrm{H}_{2} \mathrm{O}$ pada suhu $25^{\circ} \mathrm{C}$

Menurut Rizov (2012), mineral limonit yang terbentuk dari ion ferrous $\left(\mathrm{Fe}^{2+}\right)$ terjadi melalui terbentuknya terlebih dahulu fasa intermediet ferihidrat $\left(\mathrm{Fe}(\mathrm{OH})_{3}\right)$ akibat teroksidasinya ion $\mathrm{Fe}^{2+}$ di dalam larutan, menurut reaksi berikut:

$4 \mathrm{Fe}^{2+}+\mathrm{O}_{2}+10 \mathrm{H}_{2} \mathrm{O} \rightarrow 4 \mathrm{Fe}(\mathrm{OH})_{3}+8 \mathrm{H}^{+}$.

Ferihidrit merupakan senyawa yang tidak stabil, sehingga mudah terkonversi secara irreversibel menjadi limonit.

$\mathrm{Fe}(\mathrm{OH})_{3} \rightarrow \mathrm{FeOOH}+\mathrm{H}_{2} \mathrm{O}$

Peningkatan \% Berat percontoh yang hilang yang signifikan terjadi hingga suhu $350^{\circ} \mathrm{C}$. Di atas suhu tersebut tidak menunjukkan adanya peningkatan \% Berat percontoh yang hilang yang berarti. Hal ini mungkin disebabkan reaksi pelepasan molekul air yang telah selesai. Saat konsentrasi/jumlah air molekul di dalam mineral limonit habis, difusi molekul air dari bidang antar muka mineral limonit menuju ruah tidak terjadi lagi, akibat tidak terbentuknya gradien konsentrasi molekul air, sehingga tidak terjadi lagi peningkatan jumlah $\%$ Berat percontoh yang hilang. Hukum Fick's
I menjelaskan bahwa difusi flux terjadi ketika ada gradien konsentrasi dalam jarak tertentu.

$J=-D \frac{d C}{d x}$

Pada temperatur $250^{\circ} \mathrm{C}$, \% Berat percontoh yang hilang hanya mencapai $9,14 \%$ dan $9,11 \%$ untuk suhu $300^{\circ} \mathrm{C}$. Nilai ini belum memenuhi nilai stoikiometri perbandingan mol 1:1 $\mathrm{Fe}_{2} \mathrm{O}_{3}$ dan $\mathrm{H}_{2} \mathrm{O}$, jika menganggap tidak ada kelebihan molekul air di dalam mineral limonit. Hal ini mungkin disebabkan temperatur yang digunakan belum cukup mampu memberikan energi untuk menghasilkan reaksi yang sempurna. Analisis mineralogi XRD dilakukan terhadap produk pada $\mathrm{t}=60$ menit dan $\mathrm{T}=250^{\circ} \mathrm{C}, 300^{\circ} \mathrm{C}$, serta $350^{\circ} \mathrm{C}$, dan untuk $\mathrm{T}=450^{\circ} \mathrm{C}$ dan $500^{\circ} \mathrm{C}$ produk dianggap memiliki karakteristik analisis XRD yang sama dengan $\mathrm{T}=350^{\circ} \mathrm{C}$ karena pada suhu $\mathrm{T}=350^{\circ} \mathrm{C}$, \% Berat percontoh yang hilang telah mencapai asimtotik. Hasil analisis XRD tersebut ditabulasikan pada Tabel 3.

Pada suhu $250^{\circ} \mathrm{C}$ selama 60 menit masih terdapat puncak-puncak mineral limonit yang cukup dominan. Hal tersebut memberikan 
bukti bahwa suhu $250^{\circ} \mathrm{C}$ belum cukup memberikan pengaruh terhadap perubahan mineral limonit untuk waktu 60 menit, namun pada suhu $300^{\circ} \mathrm{C}$ dan $350^{\circ} \mathrm{C}$ seluruh limonit telah terubah menjadi hematit. Identifikasi mineralogi XRD bijih laterit dengan $70 \% w t$ ukuran butiran $-44 \mu \mathrm{m}$ dan $100 \% \mathrm{wt}-150 \mu \mathrm{m}$ memperlihatkan adanya dominasi mineral limonit (Gambar 4(a)). Proses penghilangan air kristal pada suhu $400^{\circ} \mathrm{C}$ dan waktu 60 menit terhadap bijih laterit tersebut menyebabkan terkonversinya seluruh limonit menjadi hematit (Gambar 4(b)).

Pengaruh suhu proses penghilangan air kristal terhadap sifat kemagnetan untuk beberapa percontoh hasil percobaan, dilakukan pengukuran kemagnetan menggunakan alat Permagraph. Data yang diperoleh dari hasil pengujian sifat magnet tersebut masingmasing disajikan pada Tabel 2, dan untuk grafik pengukuran sifat magnet disajikan pada Gambar 5.

Tabel 3. Hasil analisis mineralogi XRD produk penghilangan air kristal

\begin{tabular}{cccc}
\hline $\begin{array}{c}\text { Temperatur } \\
\left({ }^{\circ} \mathrm{C}\right)\end{array}$ & Senyawa yang terdeteksi & $\begin{array}{c}\text { Berat percontoh yang hilang } \\
(\%)\end{array}$ & $\begin{array}{c}\text { Kadar Fe total } \\
(\%)\end{array}$ \\
\hline 250 & Limonit, Hematit & 9,1 & 55,0 \\
300 & Hematit & 10,6 & 56,0 \\
350 & Hematit & 11,3 & 56,4 \\
450 & Hematit & 11,3 & 56,4 \\
500 & Hematit & 11,3 & 56,4 \\
\hline
\end{tabular}

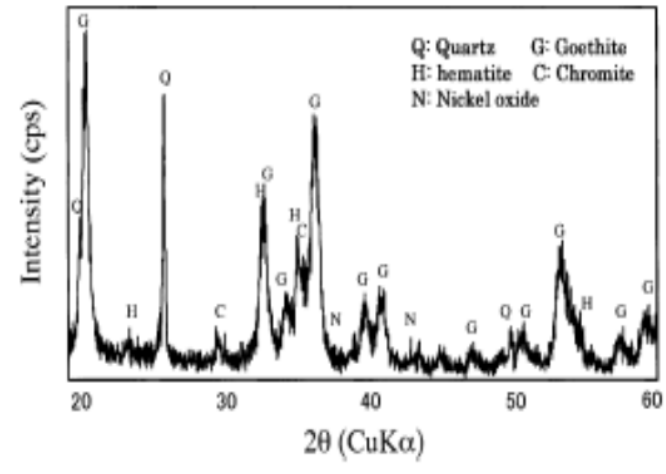

(a)

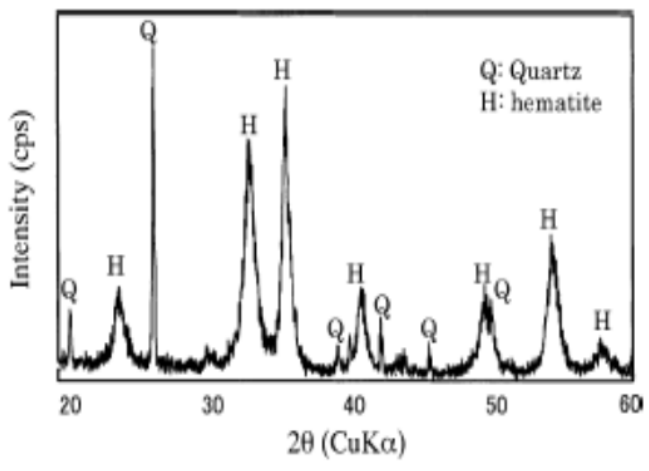

(b)

Gambar 4. (a) Percontoh awal bijih laterit (b) Hasil dehidrasi bijih laterit pada suhu $400^{\circ} \mathrm{C}$ selama 60 menit

Tabel 4. Hasil pengujian sifat magnet untuk contoh produk dehidrasi $450^{\circ} \mathrm{C}$ dan $500^{\circ} \mathrm{C}$

\begin{tabular}{cccc}
\hline & \multicolumn{3}{c}{ Sifat Magnet } \\
\hline Parameter & $450^{\circ} \mathrm{C}$ & $500{ }^{\circ} \mathrm{C}$ & Besaran Satuan \\
\hline $\mathrm{Br}$ & 0.00 & 0.03 & $\mathrm{kG}$ \\
$\mathrm{HcB}$ & 0.000 & 0.020 & $\mathrm{kOe}$ \\
$\mathrm{HcJ}$ & 0.100 & $>14.400$ & $\mathrm{kOe}$ \\
$\mathrm{H}$ knee & 0.100 & 0.000 & $\mathrm{kOe}$ \\
$(\mathrm{BH})$ max & 0.00 & 0.00 & $\mathrm{MGOe}$ \\
$\mathrm{Ba}$ & 0.600 & 0.11 & $\mathrm{kG}$ \\
$\mathrm{Ha}$ & 0.600 & 0.100 & $\mathrm{kOe}$ \\
$\mathrm{H}$ max & 14.400 & 14.300 & $\mathrm{kOe}$ \\
\hline
\end{tabular}




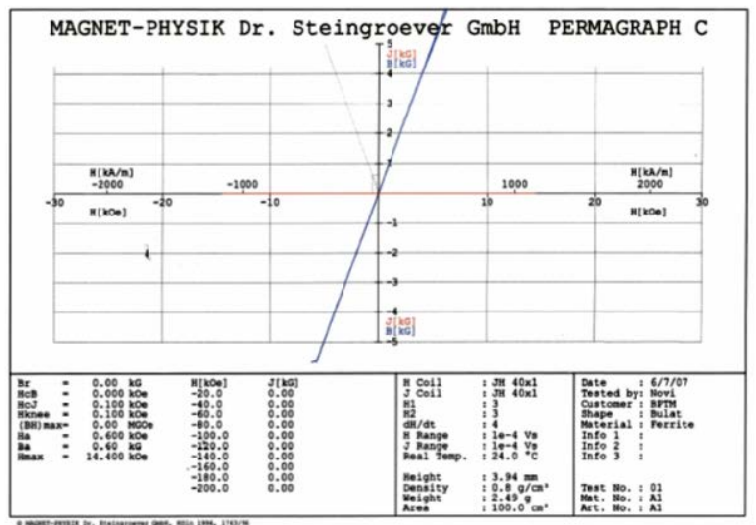

(a)

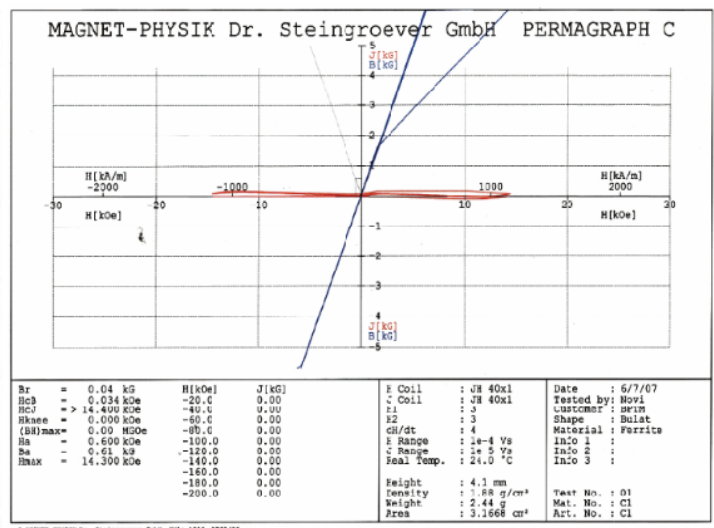

(b)

Gambar 5. Grafik hasil pengukuran sifat magnet untuk produk dehidrasi (a) $450^{\circ} \mathrm{C}$ (b) $550^{\circ} \mathrm{C}$

Dari data pengukuran parameter sifat magnet bahan seperti disajikan pada Tabel 4, terlihat terjadinya peningkatan nilai besaran parameter sifat magnet dengan naiknya suhu proses penghilangan air kristal, terutama untuk besaran parameter $\mathrm{Br}$ (remanence magnetic flux density) sebagai sifat magnet bahan yang mempengaruhi besaran magnetic intensity alat magnetic separator sehingga bahan tersebut dapat ditarik (mempunyai gaya (force)). Pada suhu proses " annealing" $450^{\circ} \mathrm{C}$ dengan nilai $\mathrm{Br}$ $=0.00 \mathrm{kG}$, naik menjadi 0,03 $\mathrm{kG}$ pada suhu $550^{\circ} \mathrm{C}$. Nilai $\mathrm{Br}$ yang diperoleh, belum mencapai nilai $\mathrm{Br}$ sebagai maghemite (70-80 $k G)$, tetapi masih bersifat hematite $(\mathrm{Br}<1 \mathrm{kG})$.

\section{Kinetika Proses}

Dari hasil percobaan yang diperoleh, disusun analisis yang dapat menjelaskan fenomena yang mungkin terjadi pada proses penghilangan air kristal mineral limonit menjadi hematit. Proses ini dilakukan pada rentang suhu $250^{\circ} \mathrm{C}$ s.d. $500^{\circ} \mathrm{C}$ dengan waktu proses 60 menit dan debit nitrogen 1 Liter/menit. Parameter yang digunakan untuk melihat hasil optimal dari masing-masing variabel temperatur adalah jumlah \% Berat percontoh yang hilang selama proses serta perubahan persen Fetotal melalui perhitungan. Secara teoritis produk yang dihasilkan dari proses penghilangan air kristal mineral limonit adalah hematit. Untuk itu dilakukan pembuktian melalui analisis komposisi mineralogi (XRD), serta menentukan perbandingan jumlah mol $\mathrm{Fe}_{2} \mathrm{O}_{3}$ dan $\mathrm{H}_{2} \mathrm{O}$.

Observasi kinetika proses perubahan limonit menjadi hematit sebagai fungsi dari perubahan temperatur telah dilakukan oleh beberapa peneliti (Zhang dkk., 2010; Das dkk., 2011; Rzepa $d k k ., 2016)$. Dalam penelitian ini, reaksi penghilangan air kristal mineral limonit merupakan reaksi yang berlangsung secara seri, dan yang mungkin bertindak sebagai pengendali reaksi hanya reaksi kimia di antar muka mineral limonit dan proses difusi uap air keluar dari mineral limonit. Untuk dapat menentukan pengendali reaksi pada proses penghilangan air mineral limonit ini, digunakan persamaan permodelan kinetika reaksi dengan menggunakan model inti menyusut (shrinking-core model) dan asumsi partikel berbentuk silinder. Persamaan permodelan kinetika dapat dituliskan sebagai berikut :

$\frac{\mathbf{b C k t}}{\mathbf{\rho R}}=\mathbf{1}-(\mathbf{1}-\boldsymbol{\alpha})^{1 / 2}$ (terkendali reaksi kimia). (8)

$\frac{\mathbf{6 b C D t}}{\rho \mathrm{R}^{2}}=\boldsymbol{\alpha}+(\mathbf{1}-\boldsymbol{\alpha}) \ln (\mathbf{1}-\boldsymbol{\alpha}) \quad$ (terkendali proses difusi)

Aluran waktu (t) terhadap 1-(1- $\alpha)^{1 / 2}$ dan $\alpha+(1-$ $\alpha) \ln (1-\alpha)$ pada masing-masing pengendali reaksi menghasilkan nilai koefisien korelasi $\left(R^{2}\right)$ tertentu. Nilai koefisien korelasi yang terbesar bertindak sebagai pengendali reaksi, karena hasil percobaan mendekati persamaan permodelan kinetika tersebut.

Penggunaan waktu untuk penentuan pengendali reaksi dilakukan hingga waktu 60 menit. Pada waktu sama dengan nol nilai $\boldsymbol{\alpha}$ dianggap nol, karena reaksi belum terjadi. Dari hasil perhitungan diperoleh hasil sebagai berikut. 


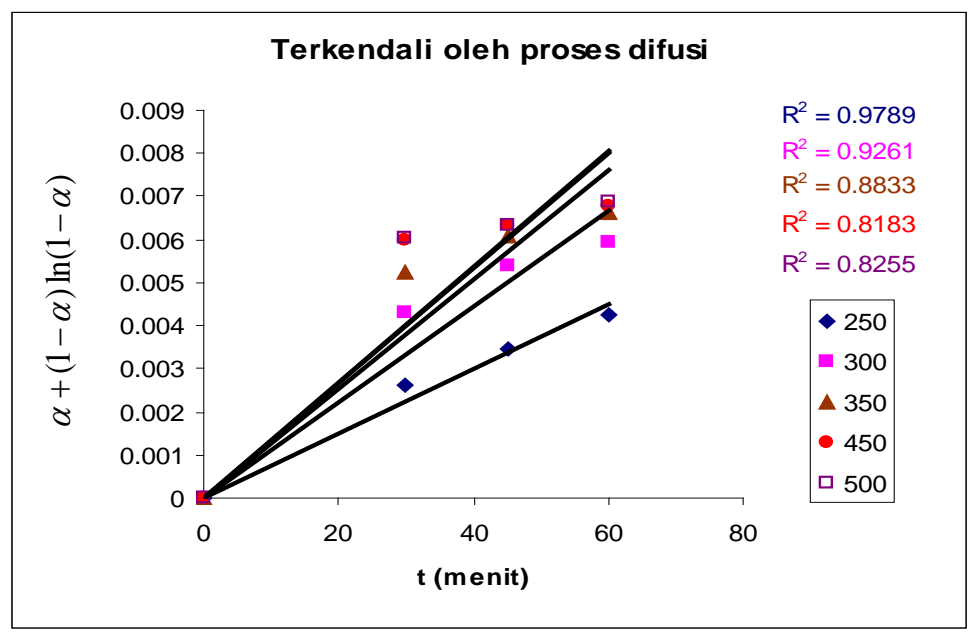

(a)

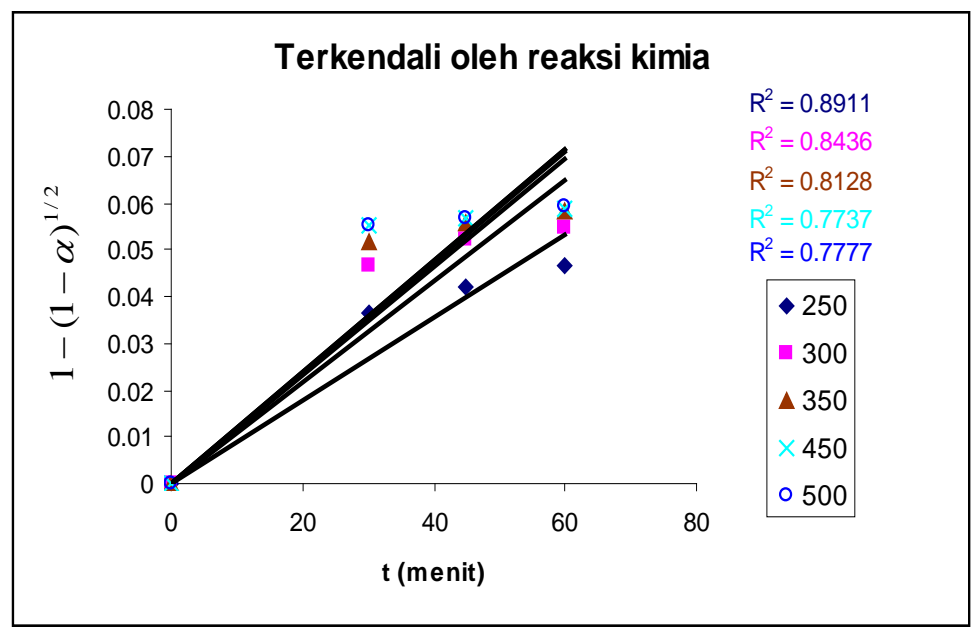

(b)

Gambar 6 Penentuan pengendali reaksi (a) terkendali oleh difusi (b) terkendali oleh reaksi kimia

Dari Gambar 6 dapat dilihat bahwa nilai koefisisen korelasi $\left(R^{2}\right)$ untuk proses terkendali oleh difusi lebih besar dari reaksi kimia untuk setiap suhu. Namun untuk proses terkendali oleh difusi, hanya pada suhu $250^{\circ} \mathrm{C}$ dan $300^{\circ} \mathrm{C}$ saja yang nilai koefisien korelasi mendekati satu, yang berarti sesuai dengan persamaan permodelan kinetika yang diajukan. Oleh karenanya proses difusi dapat dikatakan sebagai pengendali reaksi pada rentang waktu 0-60 menit untuk suhu $250^{\circ} \mathrm{C}$ dan $300^{\circ} \mathrm{C}$. Proses terkendali difusi dapat terjadi sesuai dengan pernyataan Rzepa $d k k$. (2016) bahwa reaksi terkendali sebagian oleh proses difusi pada tahap awal proses penghilangan air kristal. Hal itu diakibatkan oleh berlangsung lambatnya proses migrasi ion hidroksil dan proton keluar dari struktur kristal sepanjang $b$ axis (sumbu b). Laju difusi dipengaruhi oleh koefisien difusi ruah $\left(D_{A B}\right)$ dan koefisien difusi Knudsen $\left(\left(D_{K}\right)_{A}\right)$ untuk produk yang bersifat porous, dan nilai koefisien yang paling rendah yang bertindak sebagai pengendali laju difusi. Asumsi produk yang terbentuk bersifat porous mengacu pada pernyataan Rzepa dkk. (2016) bahwa reaksi penghilangan air kristal mineral limonit berawal dari permukaan kristal limonit menuju pusat kristal limonit dengan membentuk lapisan porous yang tegak lurus dengan c-axis (sumbu c) pada struktur kristal mineral limonit. Proses penghilangan air kristal yang terkendali oleh difusi pada $250^{\circ} \mathrm{C}$ dan $300^{\circ} \mathrm{C}$ kemungkinan disebabkan rendahnya nilai koefisien difusi, sehingga diperoleh nilai flux difusi yang rendah walaupun terdapat gradien konsentrasi yang cukup besar, akibatnya difusi berjalan lambat. 
$J=-D \frac{d C}{d x}$

Rendahnya nilai koefisien difusi dapat diakibatkan oleh terbentuknya saluran pori dengan jari-jari pori kecil, sehingga laju difusi akan terkendali oleh koefisien difusi Knudsen.

Peningkatan temperatur akan meningkatkan nilai koefisien difusi ruah dan Knudsen, yang akan berpengaruh terhadap peningkatan laju difusi, sesuai dengan persamaan berikut ini :

$$
\begin{aligned}
& D_{A B}=0,0018583 \frac{T^{3 / 2}\left(1 / M_{A}+1 / M_{B}\right)^{1 / 2}}{p \square_{A B}^{2} \Omega_{A B}} \\
& \left(D_{K}\right)_{A}=9,7 \times 10^{3} \mathrm{a}\left(\frac{T}{M_{A}}\right)^{1 / 2}
\end{aligned}
$$

Peningkatan temperatur juga berpengaruh secara termodinamika terhadap meningkatnya tekanan disosiasi reaksi dehidrasi (terjadi peningkatan jumlah uap air yang terlepas di dalam mineral limonit), sehingga meningkatkan gradien konsentrasi. Dengan meningkatnya koefisien difusi dan gradien konsentrasi terhadap peningkatan temperatur, otomatis berpengaruh terhadap peningkatan flux difusi, sehingga laju difusi berlangsung lebih cepat, sesuai dengan hukum Fick's I. Hal ini menjelaskan mengapa pada temperatur yang lebih tinggi, proses penghilangan air kristal tidak dikendalikan lagi oleh proses difusi. Reaksi penghilangan air kristal mineral limonit dapat terkendali oleh proses difusi kemudian berganti menjadi terkendali proses pengintian acak.

\section{KESIMPULAN}

Temperatur sangat berpengaruh terhadap spontanitas reaksi penghilangan air mineral limonit. Jumlah \% Berat percontoh yang hilang dan \% Fe perhitungan meningkat seiring dengan peningkatan temperatur proses. Jumlah \% Berat percontoh yang hilang dan \% Fe perhitungan meningkat secara signifikan hingga suhu $350^{\circ} \mathrm{C}$, di atas suhu tersebut jumlah \% Berat percontoh yang hilang dan \% Fe perhitungan tidak menunjukkan peningkatan. Temperatur $350^{\circ} \mathrm{C}$ merupakan temperatur optimal dengan \% berat percontoh yang hilang sebesar 11,3\% dan peningkatan kadar Fetotal menjadi 56,4\%.
Kadar besi ini dikatagorikan sebagai kadar bijih besi rendah dan belum memenuhi kadar minimum untuk industri besi baja. Upaya untuk meningkatkan kadar Fe lebih lanjut mencapai $>62 \%$, diperlukan alternatif proses konsentrasi lain seperti salah satunya dengan teknik flotasi. Dari hasil studi kinetika, pada percobaan penghilangan air kristal mineral limonit ini, reaksi pengubahan mineral limonit menjadi hematit terkendali oleh proses difusi pada suhu $250^{\circ} \mathrm{C}$ dan $300^{\circ} \mathrm{C}$.

\section{UCAPAN TERIMA KASIH}

Penulis mengucapkan terima kasih dan apresiasi kepada Pusat Penelitian dan Pengembangan Teknologi Mineral dan Batubara yang telah membiayai kegiatan penelitian ini. Terima kasih disampaikan pula kepada PT Vale Tbk yang telah menyuplai bijih laterit nikel sebagai bahan penelitian, serta kepada para laboran Laboratorium Kimia Puslitbang Tekmira yang telah membantu melakukan analisis mineralogi dan kimia.

\section{DAFTAR PUSTAKA}

Astuti, W., Zulhan, Z., Shofi, A., Isnugroho, K., Nurjaman, F. and Prasetyo, E. (2015) "Pembuatan nickel pig iron (NPI) dari bijih nikel laterit Indonesia menggunakan mini blast furnace," in Prosiding Seminar InSINaS 2012. Lembaga Ilmu Pengetahuan Indonesia, pp. 66-71.

Das, S., Hendry, M. J. and Essilfie-Dughan, J. (2011) "Transformation of two-line ferrihydrite to goethite and hematite as a function of $\mathrm{pH}$ and temperature," Environmental Science \& Technology, 45(1), pp. 268-275. doi: 10.1021/es101903y.

Dzemua, G. L. and Gleeson, S. A. (2012) "Petrography, mineralogy, and geochemistry of the Nkamouna serpentinite: implications for the formation of the cobalt-manganese laterite deposit, Southeast Cameroon," Economic Geology, 107(1), pp. 25-41. doi: 10.2113/econgeo.107.1.25.

Elias, M. (2013) Nickel laterites in South East Asia, East Asia: Geology, Exploration Technologies and Mines. Bali: CSA Global. 
Epikhin, A. N. and Krylova, A. V. (2003) "No Title," Russian Journal of Applied Chemistry, 76(1), pp. 20-22. doi: 10.1023/A:1023371228302.

Ezhov, A. M. and Shvaljov, Y. B. (2015) "Dry Magnetic Separation of Iron Ore of the Bakchar Deposit," Procedia Chemistry, 15, pp. 160166. doi: 10.1016/j.proche.2015.10.026.

de Faria, D. L. A. and Lopes, F. N. (2007) "Heated goethite and natural hematite: Can Raman spectroscopy be used to differentiate them?," Vibrational Spectroscopy, 45(2), pp. 117121. doi: 10.1016/j.vibspec.2007.07.003.

Gilroy, A. (2014) Why the quality spread on iron ore products is widening, http://marketrealist.com/2014/07/why-thequality-spread-on-iron-ore-products-iswidening/.

Jang, K., Nunna, V. R. M., Hapugoda, S., Nguyen, A. V. and Bruckard, W. J. (2014) "Chemical and mineral transformation of a low grade goethite ore by dehydroxylation, reduction roasting and magnetic separation," Minerals Engineering, 60, pp. 14-22. doi: 10.1016/j.mineng.2014.01.021.

Pardiarto, B. (2011) "Peluang bijih besi dalam pemenuhan kebutuhan komoditas mineral strategis nasional," Buletin Sumber Daya Geolologi, 6(2), pp. 59-70.

Rizov, B. (2012) "Phase transformations from goethite to hematite and thermal decomposition in various nickeliferous laterite ores," Journal of the University of Chemical Technology and Metallurgy, 47(2), pp. 207-210.

Rzepa, G., Bajda, T., Gaweł, A., Debiec, K. and Drewniak, L. (2016) "Mineral transformations and textural evolution during roasting of bog iron ores," Journal of Thermal Analysis and Calorimetry, 123(1), pp. 615-630. doi: 10.1007/s10973-015-4925-1.

Strezov, V., Evans, T. J., Zymla, V. and Strezov, L. (2011) "Structural deterioration of iron ore particles during thermal processing," International Journal of Mineral Processing, 100(1-2), pp. 27-32. doi:

10.1016/j.minpro.2011.04.005.

Zhang, W.-J., Huo, C.-F., Feng, G., Li, Y.-W., Wang, J. and Jiao, H. (2010) "Dehydration of goethite to hematite from molecular dynamics simulation," Journal of Molecular Structure: THEOCHEM, 950(1-3), pp. 20-26. doi: 10.1016/j.theochem.2010.03.013. 
